\title{
A possible role for hydrochlorothiazide (HCTZ) as “enhancer" of zofenopril activity at the tissue level
}

\author{
Claudio Borghi*, Federico Maria Verardi and Ilenia Pareo \\ *Correspondence: claudio.borghi@unibo.it \\ Department of Internal Medicine, Malpighi Hospital, Bologna University, Italy.
}

\begin{abstract}
Background: Combination therapy with an angiotensin-converting enzyme (ACE) inhibitor and a thiazide diuretic has proven to be effective in the treatment of hypertension with or without end-organ damage.

Discussion: The mechanism of action of such a combination therapy may involve a opposite effect on the renin-angiotensinaldosterone system (RAAS) with possible "functional" synergistic effects. Indeed, while diuretics can initially reduce intravascular volume leading to an activation of the RAA system with consequent vasoconstriction and salt and water retention, the concomitant presence of an ACE inhibitor may prevent such a counterregulatory response on neurohumoral system. This creates the conditions for the achievement of a maximal antihypertensive effect for both the ACE inhibitor and the diuretic. In recent years, however, experimental evidence has suggested that in addition to the above described mechanism of action, which is common to all the combinations of ACE-inhibitors and diuretics, it can be possible to identify some additional and peculiar mechanisms involving some selected drugs. Such additional mechanisms would be essentially related to some differences in the pharmacokinetic profiles of ACE inhibitors. In particular, the extent of lipophilicity could play an important role in membrane penetration and tissue accumulation and has been correlated with the overall ACE-inibitory activity of various compounds, eg., tissue ACE inhibitory activity could increase with the increase of lipophilicity. For instance, in rats with myocardial infarction, volume depletion induced by concomitant administration of HCTZ can increase the tissue levels of zofenoprilat (the active metabolite of zofenopril, an highly lipophilic ACE inhibitor), but not those of the highly hydrophilic lisinopril. An interesting hypothesis is that associating HCTZ to a highly lipophilic ACE inhibitor translates into peculiar clinical profiles, therefore we suggest further studies on this matter. Conclusion: Experimental models have shown that hydrochlorothiazide (HCTZ) could act like a "tissue levels enhancer" of lipophilic ACE-inhibitors, eg., can increase tissue concentrations of zofenoprilat (active metabolite of zofenopril, an highly lipophilic compound), and consequently induce an enhancement of its tissue ACE inhibition. On the basis of available experimental data, we suggest a peculiar interaction between zofenopril and HCTZ, i.e., HCTZ could act as a "tissue levels enhancer" of zofenopril. This hypothesis, if confirmed, could imply a relevant therapeutic advantage for the treatment of arterial hypertension.
\end{abstract}

Keywords: ACE inhibitors, zofenopril, thiazide diuretics, hydrochlorothiazide, lipophilicity, ACE tissue inhibition, hypertension, combination therapy, enhancer

\section{Introduction}

Hypertension is the most common independent risk factor for cardiovascular (CV) diseases and responsible for a large proportion of morbidity and mortality in developed countries [1].

It has been recognized that the activation of the renin-angiotensin-aldosterone system (RAAS) plays a relevant role in the pathophysiological mechanisms of essential hypertension $[2,3]$. Angiotensin II has been shown to have a deleterious effect at different levels including the cardiac, vascular and renal tissues [4]. Pharmacological agents such as ACE inhibitors, that actively prevent the formation of angiotensin II, may therefore have favourable effects in terms of end-organ protewction, beyond their activity on blood pressure (BP) [5].

Furthermore, it is now recognized that to achieve optimal $\mathrm{BP}$ control the majority of patients will require at least two antihypertensive drugs, belonging to different pharmacologic classes [6].

\begin{abstract}
Discussion
Combination therapy with an ACE inhibitor plus a thiazide diuretic

Combination therapy with an angiotensin-converting-enzyme (ACE) inhibitor plus a low-dose thiazide diuretic (eg., hydrochlorothiazide - HCTZ) has many advantages in the treatment of hypertension, i.e., it can effectively reduce BP levels, prevent end-organ damage and reduce the probability of adverse metabolic effects often caused by the administration of an high dose of diuretic therapy $[7,8]$.

The mechanism of action of such a combination therapy may involve a synergistic and opposite effect on the reninangiotensin-aldosterone system (RAAS) [9]. Diuretic therapy can initially reduce plasma volume with a consequent increase in plasma renin activity, aldosterone secretion and urinary potassium loss [9]. Conversely, ACE inhibitors block the production of angiotensin II while counteract the reactive
\end{abstract}


Borghi et al. Cardiovascular System 2013,

hyperreninemia that may reduce the antihypertensive effect of diuretics. Therefore the combination of the two drugs seems specifically designed to promote the maximal antihypertensive effect of both classes of drugs [9].

Because of this combined effect, the dosages of each agent needed to achieve adequate blood pressure control are less than those required in monotherapy; this may improve tolerability, reducing adverse effects of single components [10].

In recent years, however, some experimental evidences have suggested that, in addition to the above reported mechanism of action which is common to all ACE inhibitors/diuretics combinations, it might be possible to identify some additional pharmacological mechanisms that are peculiar of some of these combinations [11]. Such additional mechanisms would be essentially related to the pharmacological characteristics of ACE inhibitors, particularly in terms of their different profile of lipophilicity [11].

\section{Impact of lipophilicity on tissue concentrations of ACE inhibitors}

Lipophilicity plays a relevant role in membrane penetration and tissue accumulation, and has been correlated with activity of various drugs, eg., tissue ACE inhibitory activity could be higher for lipophilic compounds [11,12].

The lipophilicity of various ACE inhibitors has been evaluated in vitro by determining octanol-water distribution coefficients (the higher the value of the coefficient, the greater the lipophilicity of the drug) [12]. ACE inhibitors show a wide spectrum of lipophilicity. Zofenopril, for example, is an highly lipophilic ACE inhibitor, showing an octanol-water distribution coefficient 35 at $\mathrm{pH}$ 7, while lisinopril is a very hydrophilic ACE inhibitor, showing an octanol-water distribution coefficient $<0.001$ at $\mathrm{pH} 7$ [12].

Zofenopril is chemically characterized by the presence of a sulphydryl (SH) group [13]. Zofenopril and its active metabolite zofenoprilat are highly lipophilic, more than other ACE inhibitors [14]. The high lipophilicity of zofenopril allows effective and long-lasting tissue penetration [15-17]; furthermore, zofenopril has a sustained activity on cardiac ACE inhibition, antioxidant properties and remarkable tissue protective effect [18] and can improve oxidative stress in patients with essential hypertension [19].

\section{Effect of HCTZ administration on ACE inhibitors pharmacokinetics}

Volume depletion induced by concomitant administration of HCTZ can significantly influence steady-state plasma and tissue levels of ACE inhibitor [11]. The effect of concomitant administration of HCTZ could differ, however, depending on the lipophilicity of the ACE inhibitor, i.e., resulting in increased plasma ACE inhibitor levels in case of hydrophilic compounds (eg., lisinopril) versus increased tissue ACE inhibitor levels in case of lipophilic compounds (eg., zofenopril) [11].

Interestingly, an experimental study on rats showed remarkable different pharmacokinetics of two ACE inhibitors, lisinopril and zofenopril, in condition of volume depletion induced by concomitant administration of HCTZ [11]. The main hypothesis of this study is that sodium and water depletion induced by diuretic therapy can increase the efficacy of ACE inhibitor in the treatment of hypertension and renal dysfunction. The same mechanism might apply to the treatment of left ventricular dysfunction after myocardial infarction [11].

In the above mentioned study, myocardial infarction was induced in rats through coronary ligation; after 1 week, they were randomized to $50 \mathrm{mg} / \mathrm{kg} /$ day hydrochlorothiazide or to control treatment for 3 weeks. The last week, the animals received lisinopril or zofenopril in equipotent dosages (3.3 and $10 \mathrm{mg} / \mathrm{kg} /$ day, respectively). They were sacrificed after the last dose of ACE inhibitor and tissues were collected to evaluate drug concentrations. Lisinopril concentrations in plasma were significantly increased by HCTZ, whereas lisinopril tissue levels remained unchanged; on the contrary, plasma concentrations of zofenoprilat (the active metabolite of zofenopril) were only marginally increased by HCTZ, whereas zofenoprilat accumulation in both cardiac and renal tissues was markedly increased (Figure 1) [11].

These findings may be related to volume depletion induced in the rats by the concomitant administration of HCTZ; rather than leading to increased plasma levels, as in the case of lisinopril, the lipophilic nature of zofenopril would favor drug penetration of this ACE inhibitor into the tissue, with a subsequent tissue accumulation of the active metabolite zofenoprilat [11].

The possible interpretation of these findings is that HCTZ could act like a "tissue levels enhancer", i.e., HCTZ can increase tissue concentrations of zofenopril and induce a peculiar enhancement of the tissue activity of this lipophilic ACE inhibitor [11].

\section{Peculiar characteristics of the fixed combination zofenopril plus HCTZ}

Therapy with ACE inhibitors can ameliorate myocyte contractile function [20], reduce collagen deposition and nonmyocyte cellular proliferation $[20,21]$ and prevent myocyte hypertrophic response $[\mathbf{2 0}, \mathbf{2 1}]$. In addition, it has also been demonstrated that ACE inhibitors can counteract the vasoconstriction of the atherosclerotic coronary arteries [4]. Treatment with ACE inhibitors has also prevented endothelial dysfunction both in animal [22-26] and in human experiments [27-31]. The favourable effects of ACE inhibitors seem to be related to their ability to release local vasodilators such as nitric oxide (NO) as well as to antagonize the vasoconstrictive effects of angiotensin II [32]. In addition, ACE inhibitors can counteract several atherosclerotic processes, including proliferation of vascular smooth muscle cells, low-density lipoprotein (LDL) oxidation, local accumulation of neutrophils and thrombosis [33]. 
Borghi et al. Cardiovascular System 2013,

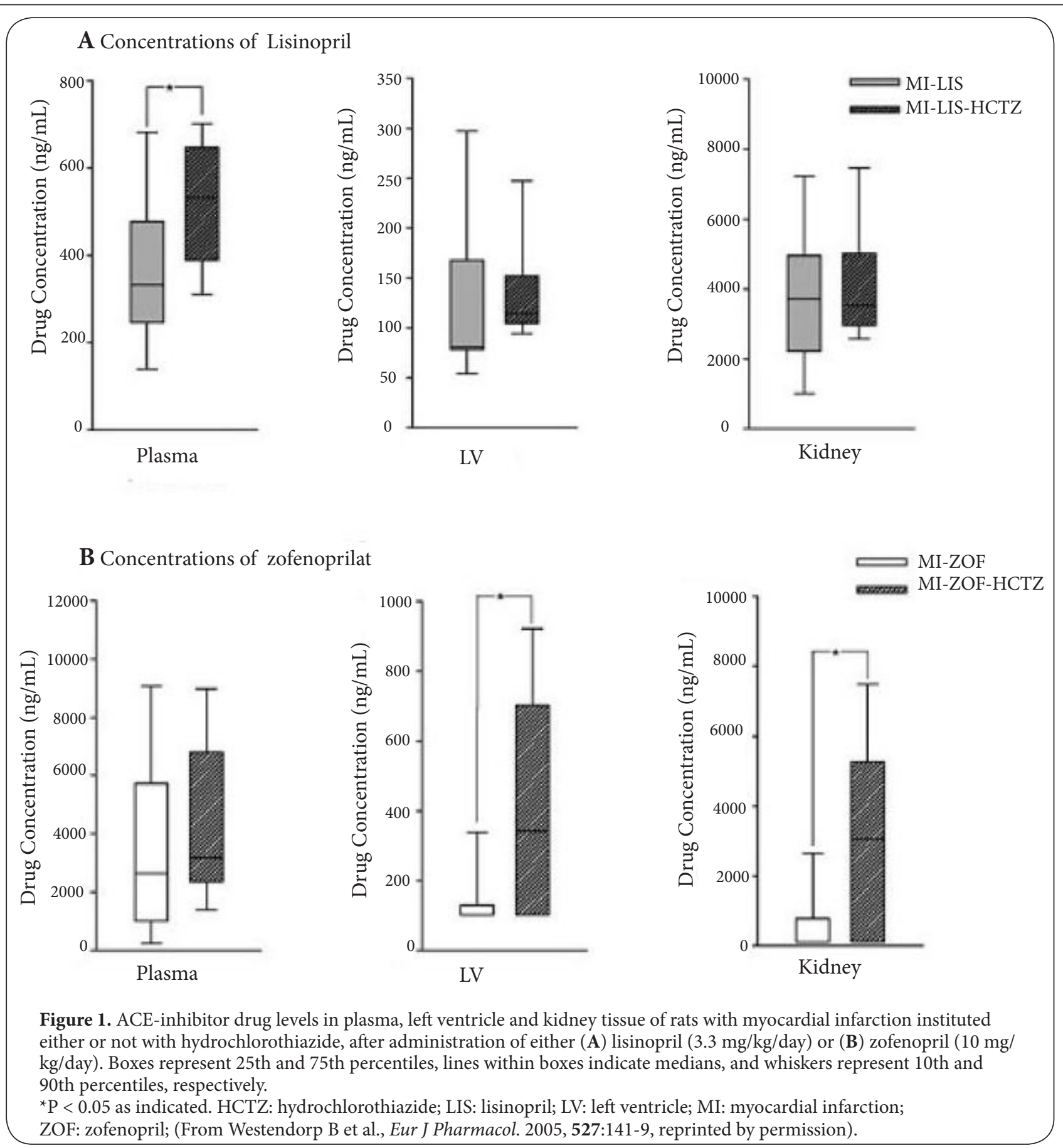

The increase in tissue levels of ACE inhibitor, determined by concomitant administration of $\mathrm{HCTZ}$, could contribute to the development of organ-protective effects of ACE inhibitor therapy; therefore, an highly lipophilic ACE inhibitor, such as zofenopril, would take advantage of co-administration with HCTZ, in comparison to an hydrophilic ACE inhibitor, such as lisinopril [11].

The aim of this paper is not to compare different drug combination treatments for high blood pressure, or to match up different clinical trials; our goal is to open a debate in the specific context of the combination therapy between ACE inhibitors and thiazide diuretics. On the basis of available experimental data [11], we suggest a peculiar interaction between zofenopril and HCTZ, i.e., HCTZ could act as a "tissue levels enhancer" of zofenopril.

This hypothesis, if confirmed, could imply a relevant therapeutic advantage for the treatment of arterial hypertension; therefore we would hope for other Authors' studies, so to 
Borghi et al. Cardiovascular System 2013,

http://www.hoajonline.com/journals/pdf/2052-4358-1-6.pdf

obtain more evidences to confirm our theory.

\section{Conclusions}

The combination of an angiotensin-converting enzyme (ACE) inhibitor and thiazide diuretic is effective in the treatment of hypertension and end-organ protection.

Mechanism of action of such a combination may involve a synergistic and contrasting effect on the renin-angiotensinaldosterone system (RAAS).

Recent experiments, however, suggest that some of these associations may possess additional mechanisms. Experimental models, in fact, have shown that volume depletion induced by concomitant administration of HCTZ can increase tissue levels of zofenoprilat (the active metabolite of zofenopril, an highly lipophilic ACE inhibitor) but not tissue levels of lisinopril (an highly hydrophilic ACE inhibitor). Increased tissue drug levels of lipophilic ACE inhibitors may contribute to enhance their tissue activity and potentially increase their cardiovascular therapeutic effects.

On the basis of available experimental data, we suggest a peculiar interaction between zofenopril and HCTZ, i.e., HCTZ could act as a "tissue levels enhancer" of zofenopril. This hypothesis, if confirmed, could imply a relevant therapeutic advantage for the treatment of arterial hypertension.

\section{List of abbreviations}

ACE: Angiotensin-Converting Enzyme

BP: Blood Pressure

HCTZ: Hydrochlorothiazide

RAAS: Renin-Angiotensin-Aldosterone System

\section{Competing interests}

CB reports lecture fees from Menarini International, which could have economic benefits from the publication of this work.

\section{Authors' contributions}

All authors contributed extensively to the work presented in this paper.

CB wrote the main paper, FMV and IP wrote some

supplementary considerations, provided full

bibliographic support, and edited the manuscript.

All authors discussed the results and implications and

commented on the manuscript at all stages.

Publication history

Editor: Carl J. Pepine, University of Florida College of Medicine, USA.

Received: 02-Apr-2013 Revised: 24-May-2013

Accepted: 01-Jul-2013 Published: 06-Jul-2013

\section{References}

1. Ezzati M, Lopez AD, Rodgers A, Vander Hoorn S and Murray CJ: Selected major risk factors and global and regional burden of disease. Lancet 2002, 360:1347-60. | Article | PubMed

2. Toto RD, Rinner S and Ram CV: ACE inhibitors and target organ protection. An expanded role for these antihypertensive agents? Postgrad Med 2004, 116:11-6. | PubMed

3. Dzau V: The cardiovascular continuum and renin-angiotensinaldosterone system blockade. J Hypertens Supp/ 2005, 23:S9-17. | Article I PubMed

4. Khalil ME, Basher AW, Brown EJ, Jr. and Alhaddad IA: A remarkable medical story: benefits of angiotensin-converting enzyme inhibitors in cardiac patients. J Am Coll Cardiol 2001, 37:1757-64. | $\underline{\text { Article | PubMed }}$

5. Ambrosioni $E$ : Defining the role of zofenopril in the management of hypertension and ischemic heart disorders. Am J Cardiovasc Drugs 2007, 7:17-24. | Article | PubMed

6. Kearney PM, Whelton M, Reynolds K, Muntner P, Whelton PK and He $\mathrm{J}$ : Global burden of hypertension: analysis of worldwide data. Lancet 2005, 365:217-23. | Article | PubMed

7. Mancia G, Zanchetti A, Agabiti-Rosei E, Benemio G, De Cesaris R, Fogari R, Pessina A, Porcellati C, Rappelli A, Salvetti A and Trimarco $\mathrm{B}$ : Ambulatory blood pressure is superior to clinic blood pressure in predicting treatment-induced regression of left ventricular hypertrophy. SAMPLE Study Group. Study on Ambulatory Monitoring of Blood Pressure and Lisinopril Evaluation. Circulation 1997, 95:1464 70. | Article | PubMed

8. Zanchetti A: Contribution of fixed low-dose combinations to initial therapy in hypertension. Eur Heart J Supplements 1999, 1:L5-L9. I Pdf

9. Gradman AH, Basile JN, Carter BL and Bakris GL: Combination therapy in hypertension. J Clin Hypertens (Greenwich) 2011, 13:146-54. | Article I PubMed

10. Omboni S, Malacco E and Parati G: Zofenopril plus hydrochlorothiazide fixed combination in the treatment of hypertension and associated clinical conditions. Cardiovasc Ther 2009, 27:275-88. | Article | PubMed

11. Westendorp B, Schoemaker RG, van Gilst WH, van Veldhuisen DJ and Buikema $\mathrm{H}$ : Hydrochlorothiazide increases plasma or tissue angiotensin-converting enzyme-inhibitor drug levels in rats with myocardial infarction: differential effects on lisinopril and zofenopril. Eur J Pharmacol 2005, 527:141-9. | Article | PubMed

12. Ranadive SA, Chen AX and Serajuddin AT: Relative lipophilicities and structural-pharmacological considerations of various angiotensinconverting enzyme (ACE) inhibitors. Pharm Res 1992, 9:1480-6. | Article I PubMed

13. Evangelista S and Manzini S: Antioxidant and cardioprotective properties of the sulphydryl angiotensin-converting enzyme inhibitor zofenopril. J Int Med Res 2005, 33:42-54. I Article I PubMed

14. Subissi A, Evangelista S and Giachetti A: Preclinical profile of zofenopril: an angiotensin converting enzyme inhibitor with peculiar cardioprotective properties. Cardiovasc Drug Rev 1999, 17:115 -133. | Article

15. Sun $Y$ and Mendelsohn FA: Angiotensin converting enzyme inhibition in heart, kidney, and serum studied ex vivo after administration of zofenopril, captopril, and lisinopril. J Cardiovasc Pharmacol 1991, 18:478-86. | Article | PubMed

16. Evangelista S, Criscuoli M, Manzini S: Tissue distribution of ${ }^{14} \mathrm{C}$-zofenopril, a new angiotensin converting enzyme inhibitor with high affinity for the tissues in rats. In: Recent Research Development in Drug Metabolism and Disposition (Pandalai SG, ed). Trivandrum: Transworld Research Network, 2002, pp17 - 24.

17. Matarrese M, Salimbeni A, Turolla EA, Turozzi D, Moresco RM, Poma D, Magni F, Todde S, Rossetti C, Sciarrone MT, Bianchi G, Kienle MG and Fazio F: 11C-Radiosynthesis and preliminary human evaluation of the disposition of the ACE inhibitor [11C]zofenoprilat. Bioorg Med Chem 2004, 12:603-11. | Article | PubMed

18. Borghi $C$ and Cicero AF: Fixed combination of zofenopril plus hydrochlorothiazide in the management of hypertension: a review of available data. Vasc Health Risk Manag 2006, 2:341-9. | Article | PubMed Abstract | PubMed Full Text

19. Napoli C, Sica V, de Nigris F, Pignalosa O, Condorelli M, Ignarro LJ and Liguori A: Sulfhydryl angiotensin-converting enzyme inhibition induces sustained reduction of systemic oxidative stress and improves the nitric oxide pathway in patients with essential hypertension. Am Heart J 2004, 148:e5. | Article | PubMed

20. Spinale FG, Holzgrefe HH, Mukherjee R, Hird RB, Walker JD, ArnimBarker A, Powell JR and Koster WH: Angiotensin-converting enzyme inhibition and the progression of congestive cardiomyopathy. Effects on left ventricular and myocyte structure and function. Circulation 1995, 92:562-78. I Article I PubMed 
Borghi et al. Cardiovascular System 2013,

http://www.hoajonline.com/journals/pdf/2052-4358-1-6.pdf

doi: $10.7243 / 2052-4358-1-6$

21. Taylor K, Patten RD, Smith JJ, Aronovitz MJ, Wight J, Salomon RN and Konstam MA: Divergent effects of angiotensin-converting enzyme inhibition and angiotensin II-receptor antagonism on myocardial cellular proliferation and collagen deposition after myocardial infarction in rats. J Cardiovasc Pharmacol 1998, 31:654-60. | Article I PubMed

22. Goetz RM and Holtz J: Enhanced angiotensin-converting enzyme activity and impaired endothelium-dependent vasodilation in aortae from hypertensive rats: evidence for a causal link. Clin Sci (Lond) 1999, 97:165-74. | Article | PubMed

23. Huang $\mathrm{H}$, Arnal JF, Llorens-Cortes C, Challah M, Alhenc-Gelas F, Corvol $P$ and Michel JB: Discrepancy between plasma and lung angiotensinconverting enzyme activity in experimental congestive heart failure. A novel aspect of endothelium dysfunction. Circ Res 1994, 75:454-61. Article | PubMed

24. Lewis DA, Rud KS and Miller VM: Cofactors of constitutive nitric oxide synthase and endothelium-dependent relaxations in canine femoral veins. J Cardiovasc Pharmacol 1993, 22:443-8. I Article I PubMed

25. Thuillez C, Mulder P, Elfertak L, Blaysat G, Compagnon P, Henry JP, Richard V, Scalbert E and Desche P: Prevention of endothelial dysfunction in small and large arteries in a model of chronic heart failure. Effect of angiotensin converting enzyme inhibition. Am J Hypertens 1995, 8:7S-12S. | Article I PubMed

26. Anderson T: Current trials on angiotensin-converting enzyme inhibitors and endothelial dysfunction. Can J Cardiol 1998, 14 Suppl D:33D-34D. | PubMed

27. Mancini GB, Henry GC, Macaya C, O’Neill BJ, Pucillo AL, Carere RG Wargovich TJ, Mudra H, Luscher TF, Klibaner MI, Haber HE, Uprichard $A C$, Pepine $\mathrm{CJ}$ and Pitt $\mathrm{B}$ : Angiotensin-converting enzyme inhibition with quinapril improves endothelial vasomotor dysfunction in patients with coronary artery disease. The TREND (Trial on Reversing ENdothelial Dysfunction) Study. Circulation 1996, 94:258-65. | Article I PubMed

28. Hornig B and Drexler $\mathrm{H}$ : Endothelial function and bradykinin in humans. Drugs 1997, 54 Suppl 5:42-7. | Article | PubMed

29. Mancini GB: Long-term use of angiotensin-converting enzyme inhibitors to modify endothelial dysfunction: a review of clinical investigations. Clin Invest Med 2000, 23:144-61. | Article | PubMed

30. Taddei S, Virdis A, Ghiadoni L, Mattei P and Salvetti A: Effects of angiotensin converting enzyme inhibition on endothelium-dependent vasodilatation in essential hypertensive patients. J Hypertens 1998, 16:447-56. | Article | PubMed

31. Nakamura M, Funakoshi T, Arakawa N, Yoshida H, Makita S and Hiramori $\mathrm{K}$ : Effect of angiotensin-converting enzyme inhibitors on endotheliumdependent peripheral vasodilation in patients with chronic heart failure. J Am Coll Cardiol 1994, 24:1321-7. | Article | PubMed

32. Hornig $\mathrm{B}$, Arakawa $\mathrm{N}$ and Drexler $\mathrm{H}$ : Effect of ACE inhibition on endothelial dysfunction in patients with chronic heart failure. Eur Heart J 1998, 19 Suppl G:G48-53. | Article | PubMed

33. Mancini GB: Emerging concepts: angiotensin-converting enzyme inhibition in coronary artery disease. Cardiovasc Drugs Ther 1996, 10 Suppl 2:609-12. | Article | PubMed

\section{Citation:}

Borghi C, Verardi FM and Pareo I: A possible role for hydrochlorothiazide (HCTZ) as "enhancer" of zofenopril activity at the tissue level. Cardio Vasc Syst 2013, 1:6.

http://dx.doi.org/10.7243/2052-4358-1-6 